Basic Neuroscience

\title{
Simultaneous recording of hippocampal oxygen and glucose in real time using constant potential amperometry in the freely-moving rat
}

\author{
John Kealy*, Rachel Bennett, John P. Lowry \\ Department of Chemistry, National University of Ireland Maynooth, Maynooth, Co. Kildare, Ireland
}

\section{H I G H L I G H T S}

- We show that average concentrations of hippocampal oxygen and glucose are $100.26 \pm 5.76 \mu \mathrm{M}$ and $0.60 \pm 0.06 \mathrm{mM}$ respectively.

- We show that there are uncoupled changes in oxygen and glucose during neuronal activation.

- Anaesthesia and carbonic anhydrase inhibition both significantly increase hippocampal oxygen.

- Anaesthesia, dimethyl sulfoxide administration and carbonic anhydrase inhibition significantly increase hippocampal glucose.

- We show that changes in hippocampal metabolism can be detected in real time using constant potential amperometry.

\section{A R T I C L E I N F O}

\section{Article history:}

Received 13 November 2012

Received in revised form 31 January 2013

Accepted 22 February 2013

\section{Keywords:}

Sensor

Biosensor

Metabolism

Anaesthesia

Dimethyl sulfoxide

Acetazolamide

\begin{abstract}
A B S T R A C T
Amperometric sensors for oxygen and glucose allow for real time recording from the brain in freelymoving animals. These sensors have been used to detect activity- and drug-induced changes in metabolism in a number of brain regions but little attention has been given over to the hippocampus despite its importance in cognition and disease. Sensors for oxygen and glucose were co-implanted into the hippocampus and allowed to record for several days. Baseline recordings show that basal concentrations of hippocampal oxygen and glucose are $100.26 \pm 5.76 \mu \mathrm{M}$ and $0.60 \pm 0.06 \mathrm{mM}$ respectively. Furthermore, stress-induced changes in neural activity have been shown to significantly alter concentrations of both analytes in the hippocampus. Administration of $\mathrm{O}_{2}$ gas to the animals' snouts results in significant increases in hippocampal oxygen and glucose and administration of $\mathrm{N}_{2}$ gas results in a significant decrease in hippocampal oxygen. Chloral hydrate-induced anaesthesia causes a significant increase in hippocampal oxygen whereas treatment with the carbonic anhydrase inhibitor acetazolamide significantly increases hippocampal oxygen and glucose. These findings provide real time electrochemical data for the hippocampus which has been previously impossible with traditional methods such as microdialysis or ex vivo analysis. As such, these sensors provide a window into hippocampal function which can be used in conjunction with behavioural and pharmacological interventions to further elucidate the functions and mechanisms of action of the hippocampus in normal and disease states.
\end{abstract}

(c) 2013 Elsevier B.V. All rights reserved.

\section{Introduction}

Using implantable sensors allows for stable, long-term recording of a number of common analytes in the extracellular fluid (ECF) of the brain including oxygen (Lowry et al., 1996, 1997; Lowry and Fillenz, 2001; Bolger and Lowry, 2005), glucose (Hu and Wilson, 1997; Fillenz and Lowry, 1998a; Lowry et al., 1998a,b,c; Lowry and Fillenz, 2001; Dixon et al., 2002), nitric oxide (Brown et al., 2009) and glutamate (Kulagina et al., 1999; McMahon et al., 2006a, 2006b, 2007; Qin et al., 2008; Tian et al., 2009). Unlike other methods

\footnotetext{
* Corresponding author. Tel.: +35314747165

E-mail address: John.Kealy@nuim.ie (J. Kealy).
}

such as microdialysis, electrochemical sensors are small, can record at a sub-second temporal resolution and cause less disruption in surrounding tissue compared to microdialysis guide cannulae and probes (Bungay et al., 2003; Borland et al., 2005). While limited in terms of what analytes can be measured at any one time, the high specificity and temporal resolution of sensors make them ideal for measuring the relationships between neurochemistry, metabolism and neural activity (Lowry and O'Neill, 2006).

Tissue levels of oxygen in the brain have been traditionally measured indirectly by jugular bulb oximetry (Andrews et al., 1991; Feldman and Robertson, 1997; De Deyne et al., 1998) or by using functional magnetic resonance imaging (fMRI) to monitor the blood-oxygen-level dependent (BOLD) signal (Ogawa et al., 1990; Menon et al., 1992; Glover, 2011). Oxygen can also be measured more directly by voltammetry using Clark-type electrodes 
implanted into the brain tissue (Clark et al., 1958; Krolicki and Leniger-Follert, 1980; Doppenberg et al., 1998; Gupta et al., 1999). Classical Clark electrodes are restrictive due to their large size; they have poor spatial resolution for measuring specific brain regions and are too bulky to be used reliably in freely-moving animals. More recently, these restrictions have been overcome by the development of sensors utilising constant potential amperometry (CPA) that can measure tissue oxygen levels from specific brain regions (Bolger et al., 2011a). Carbon paste electrodes (CPEs) have been shown to detect oxygen with high sensitivity and selectivity at a sub-second temporal resolution (Bolger et al., 2011b). Changes in tissue oxygen levels measured by CPEs are related to changes in regional cerebral blood flow (Lowry et al., 1997) and these changes are directly comparable to the BOLD signal from fMRI studies (Lowry et al., 2010; Francois et al., 2012). As such, tissue oxygen levels measured using CPEs can be used to assess neural activity from localised regions of the brain in freely-moving animals (Li et al., 2011; Russell et al., 2012).

Similarly, measuring tissue levels of glucose in the brain has traditionally relied on a number of indirect and direct techniques. While non-invasive measurements of brain glucose using MRI technology is possible (Choi et al., 2001), its use is not as widespread as the use of the BOLD signal in fMRI. Direct sampling of cerebral spinal fluid using microdialysis allows for local ECF levels of glucose to be determined (Sandberg et al., 1986) and for activity-related changes in glucose concentrations to be assessed (Fellows et al., 1992; McNay et al., 2000, 2001; De Bundel et al., 2009). Microdialysis is limited by its poor temporal resolution with most collection methods limited to the range of minutes, though higher temporal resolution is possible with recent advances in dialysate collection and analysis (MoralesVillagrán et al., 2008; 2012). However, the real time data acquisition made possible by glucose biosensors allow for the kind of analysis that is not currently possible using microdialysis (Lowry et al., 1998a,b,c). A number of different glucose biosensors have been developed and have been shown to be able to rapidly detect changes in cerebral glucose (Boutelle et al., 1986; Shram et al., 1997). Measuring glucose in real time with CPA can be achieved using platinum/poly(o-phenylenediamine)/glucose oxidase (Pt/PPD/GOx) biosensors (Lowry et al., 1994, 1998b; Dixon et al., 2002).

Sensors have been previously used to show the varied metabolic characteristics of different parts of the brain including the striatum (Lowry et al., 1998b; Bazzu et al., 2009; Brown et al., 2009; Calia et al., 2009), nucleus accumbens (Finnerty et al., 2012; Francois et al., 2012), motor cortex (Lowry et al., 2010), prefrontal cortex (Finnerty et al., 2012) and whisker barrel cortex (Li et al., 2011). However, there has been less attention has been afforded to the hippocampus (Freund et al., 1989; Hu and Wilson, 1997) despite its pivotal roles in declarative memory (Scoville and Milner, 1957; Cohen et al., 1999; Eacott and Easton, 2011), spatial navigation (O'Keefe and Nadel, 1978; Morris et al., 1982; D'Hooge and De Deyn, 2001) and its links to various neurodegenerative/psychiatric disorders (Heckers and Konradi, 2010; Marlatt and Lucassen, 2010; Bast, 2011; Dhikav and Anand, 2011; Bonilha et al., 2012). Therefore, there is a need for sensor data recorded in real-time to supplement the large amount of electrophysiological data (Bliss and Lomo, 1973; Martin et al., 2000; Morris et al., 2003; Colgin and Moser, 2010), microdialysis data (McNay et al., 2001; Gold, 2003; De Bundel et al., 2009; López-Pérez et al., 2012) and molecular data from tissue samples (Gooney et al., 2002; Minichiello, 2009; Barry and Commins, 2011) already published from work in the hippocampus. Some behavioural work with hippocampal sensors has been performed; it has been recently shown that oxygen sensors can be used to differentiate between the activity of the dorsal and ventral regions of the hippocampus in a spatial memory task (McHugh et al., 2011). Yet, there has been little work done using sensors to measure basal levels of oxygen and glucose in the hippocampus or to determine how basic behavioural and pharmacological interventions can alter levels of these particular analytes.

Hence, in this paper, we describe a number of experiments where tissue levels of hippocampal oxygen and glucose are simultaneously measured in the rat using CPEs and Pt/PPD/GOx sensors respectively. Alterations in hippocampal oxygen and glucose levels are detected during behavioural-induced changes in neural activity using the tail pinch and restraint stress paradigms and during periods of mild hyperoxia and hypoxia. Levels of hippocampal oxygen and glucose are also monitored following treatment with saline, the anaesthetic chloral hydrate, the commonly-used vehicle dimethyl sulfoxide and the carbonic anhydrase inhibitor acetazolamide $\left(\right.$ Diamox $\left.^{\circledR}\right)$.

\section{Materials and methods}

\subsection{Subjects}

Male Sprague Dawley rats (250-300 g; Charles River Laboratories International, Inc.; U.K.) were housed in a temperaturecontrolled facility with a $12 \mathrm{~h}$ light/dark cycle (lights on at 07:00) with access ad libitum to food and water. All procedures were performed under license in accordance with the European Communities Regulations 2002 (Irish Statutory Instrument 566/2002).

\subsection{Data acquisition and statistical analysis}

All electrochemical experiments were performed using a low noise potentiostat (Biostat IV, ACM Instruments, Cumbria, U.K.). Data acquisition was performed using a PowerLab ${ }^{\circledR}$ interface system (ADInstruments Ltd., Oxford, U.K.) and a Logiq laptop or Mac. The software packages used were LabChart for Windows and Mac (Version 6) and EChem for Windows Version 1.5.2 (ADInstruments Ltd., Oxford, U.K.).

All data was preliminarily processed in Microsoft ${ }^{\circledR}$ Excel $^{\circledR}$ for Mac 2011 (Version 14.2.2) before being exported to GraphPad Prism $^{\circledR} 5$ for Mac OS X (Version 5.0a) for statistical analysis and plotting of graphs. Data was either normalised to baseline levels for ease of comparison or area under curve (AUC) analysis was performed to quantify any observed changes in the sensor signals for statistical analysis. For multiple comparisons, repeated-measures and mixed-factorial analysis of variance tests (ANOVAs) with Bonferroni post hoc analysis were used as appropriate. Paired $t$-tests were also when comparing results from two different time points. $p<0.05$ was considered to be significant and all data is presented as the mean \pm standard error of the mean (SEM).

\subsection{Working electrode preparation and surgery}

Carbon paste (O'Neill et al., 1982) was prepared by thoroughly mixing $0.71 \mathrm{~g}$ of graphite powder (1-2 $\mu \mathrm{m}$, Aldrich) with $250 \mu \mathrm{l}$ of silicone oil (high temperature, Aldrich). CPEs were made from Teflon ${ }^{\circledR}$-coated silver wire ( 8 T, $200 \mu \mathrm{m}$ bare diameter, $256 \mu \mathrm{m}$ coated diameter; Advent Research Materials, Suffolk, U.K.) as reported previously (Lowry et al., 1997). Pt/PPD/GOx sensors were made by immobilising GOx (from Aspergillus niger; EC 1.1.3.4, type VII-S; Sigma) in a poly(o-phenylenediamine) (PPD) film by potentiometric electropolymerisation of the monomer $o$-phenylenediamine (Sigma; $300 \mathrm{mmol} / \mathrm{l}$; Geise et al., 1991) on the bare disc end of a freshly cut Teflon ${ }^{\circledR}$-coated platinum wire ( $5 \mathrm{~T}, 125 \mu \mathrm{m}$ bare diameter, $175 \mu \mathrm{m}$ coated diameter; Advent Research Materials, Suffolk, U.K.). A deoxygenated solution of 
the 0 -phenylenediamine monomer $(300 \mathrm{mmol} / \mathrm{l})$ was prepared in $10 \mathrm{ml}$ phosphate buffered saline (PBS; pH 7.4; $0.15 \mathrm{M} \mathrm{NaCl}, 0.04 \mathrm{M}$ $\mathrm{NaH}_{2} \mathrm{PO}_{4}$ and $0.04 \mathrm{M} \mathrm{NaOH}$; all from Sigma). An aliquot of $5 \mathrm{ml}$ of this solution was then added to a weighed quantity of GOx $(5 \mathrm{mg} / \mathrm{ml})$ and electropolymerised using CPA at $+700 \mathrm{mV}$ versus a saturated calomel electrode as previously described (Lowry et al., 1994).

Experiments to determine the sensitivity and selectivity for these sensor designs have previously been performed. CPEs are sensitive to changes in oxygen concentration and selective for oxygen over a range of interferent species (Bolger et al., 2011a,b). Similarly, the Pt/PPD/GOx biosensor is sensitive to changes in glucose concentration and is selective for glucose over a range of interferent species (Lowry and O'Neill, 1994; Lowry et al., 1994; 1998b). In vitro calibrations were performed using CPA in a standard threeelectrode glass electrochemical cell containing $20 \mathrm{ml}$ PBS at room temperature. A saturated calomel electrode was used as the reference electrode and a bare platinum wire served as the auxiliary electrode. The applied potential for CPEs was $-650 \mathrm{mV}$ versus a saturated calomel electrode and for Pt/PPD/GOx electrodes was $+700 \mathrm{mV}$ versus a saturated calomel electrode. For $\mathrm{CPE} \mathrm{O}_{2}$ calibrations $(0-1200 \mu \mathrm{M})$ the PBS solution was vigorously purged with $\mathrm{O}_{2}$-free $\mathrm{N}_{2}$ (BOC Ireland, average $\mathrm{O}_{2}$ content $2 \mathrm{ppm}$, maximum $\mathrm{O}_{2}$ content $5 \mathrm{ppm}$ ) for at least $30 \mathrm{~min}$ to attain adequate deaeration of the PBS solution before recording. An $\mathrm{O}_{2}$ concentration of $240 \mu \mathrm{M}$ was obtained by bubbling atmospheric air using an air pump (RENA, U.S.A.) through the PBS for a minimum of $30 \mathrm{~min}$ (Bourdillon et al., 1982; Foster et al., 1993). Finally an $\mathrm{O}_{2}$ concentration of $1200 \mu \mathrm{M}$ was obtained by bubbling pure $\mathrm{O}_{2}$ gas (BOC Ireland) through the PBS for a minimum of 30 min (Bourdillon et al., 1982; Bazzu et al., 2009). For Pt/PPD/GOx glucose calibrations (0-100 mM) aliquots of a $1 \mathrm{M}$ glucose stock solution were injected into the PBS solution in the cell. The PBS was briefly stirred using a magnetic stirring bead to uniformly mix the solution. Additionally, ascorbic acid calibrations $(0-1000 \mu \mathrm{M})$ were performed in the same manner to confirm that there was minimal interference from ascorbic acid in vivo. The current was recorded throughout the course of each experiment and analysis was performed using quiescent steady-state conditions.

For sensor implantation, animals were anaesthetised using isoflurane (4\% in air for induction, $1.5-3.0 \%$ for maintenance; IsoFlo ${ }^{\circledR}$, Abbott, U.K.) and placed in a stereotaxic frame. The skull was exposed and four anchor screws were implanted into the skull (one anchor screw doubling as the auxiliary electrode) and burr holes were made for the reference electrode and the working electrodes (see Section 2.3). The Pt/PPD/GOx sensor was implanted into the hippocampus $(-5.6 \mathrm{~mm}$ from Bregma, $+4.6 \mathrm{~mm}$ from midline, $5.1 \mathrm{~mm}$ from dorsal surface of brain; co-ordinates adapted from De Bundel et al., 2009). The CPE was implanted into the hippocampus in the same hemisphere $1.0 \mathrm{~mm}$ anterior to the $\mathrm{Pt} / \mathrm{PPD} / \mathrm{GOx}$ sensor. The sensors were cemented into place using dental cement (Dentalon ${ }^{\circledR}$ Plus, Heraeus-Kulzer, Germany) and the gold connectors at the end of each electrode were inserted into a six-pin Teflon ${ }^{\circledR}$ socket (Plastics One, U.S.A.) which was also cemented in place. All animals were given saline (0.9\%) and analgesia (Buprecare, AnimalCare Ltd., U.K.) and allowed to recover in an incubator.

\subsection{Experimental procedure}

$24 \mathrm{~h}$ following recovery, animals were singly housed in Raturn ${ }^{\circledR}$ sampling cage systems (BASi, U.S.A.) in a temperature-controlled facility with a $12 \mathrm{~h}$ light/dark cycle (lights on at 07:00) with access ad libitum to food and water. All experiments were performed in the animal's home bowl. The implanted sensors from each animal were connected to the potentiostat via the six-pin Teflon ${ }^{\circledR}$ socket using a flexible screened six core cable (Plastics One, U.S.A.). Cabling was mounted through a swivel on the Raturn ${ }^{\circledR}$ bowl to allow free movement of the animal in the bowl.

Neuronal activation was achieved using the tail pinch stress paradigm (Antelman et al., 1975; Boutelle et al., 1990) and the restraint stress paradigm (Cloutier et al., 2009). In the tail pinch stress paradigm ( $5 \mathrm{~min}$ ), a small clip is placed on the animal's tail, which induces gnawing behaviour in the animal for the period of the tail pinch. The animal is allowed to gnaw on a piece of wood and, in turn, this gnawing induces neuronal activation which will cause metabolic changes in the brain that can be detected using the sensors (Bolger and Lowry, 2005). In the restraint stress paradigm ( $5 \mathrm{~min}$ ), the animal is held immobile manually and any physical attempts to free itself are associated with neuronal activation which can be detected using the sensors in a similar manner to the tail pinch stress paradigm.

Mild hyperoxic and hypoxic conditions were produced by the administration of $\mathrm{O}_{2}$ /air and $\mathrm{N}_{2}$ /air mixtures respectively in order to verify the response of the CPEs to changes in tissue levels of oxygen (Bolger and Lowry, 2005). Each gas was delivered to the animal's snout ( $3 \mathrm{~min}$; keeping a distance of approximately $2-3 \mathrm{~cm}$ from the snout) from a gas cylinder (BOC, see Section 2.4) via plastic tubing. A flow rate of approximately $150 \mathrm{ml} / \mathrm{min}$ was used.

All injections were administered intraperitoneally (i.p.) on separate days in the following order: (1) saline ( $0.9 \%$; NaCl from Sigma; $n=6)$; (2) chloral hydrate ( $350 \mathrm{mg} / \mathrm{kg}$ in $0.9 \%$ saline; Sigma; $n=8)$; (3) dimethyl sulfoxide (DMSO; $33 \%$ in $0.9 \%$ saline; Sigma; $n=6$ ); and (4) acetazolamide (Diamox ${ }^{\circledR} ; 50 \mathrm{mg} / \mathrm{kg}$ in 33\% DMSO; Sigma; $n=6)$. Animals were weighed on each day and the respective doses for each animal were prepared immediately prior to injection.

\section{Results}

\subsection{Basal concentrations of oxygen and glucose in the hippocampus}

Caution needs to be applied when using in vitro electrode calibration data to estimate in vivo concentrations. This is primarily because of the differences between a free solution and a tissue matrix; factors such as capacitance current, diffusion, sensitivity, etc. need to be considered. However, it can be useful to determine approximate concentration data and with this in mind two time points were selected from each rat $(n=10)$ on the second day of recording (one in the day, one in the night) in order to determine extracellular concentrations for comparisons with previously reported work. The second day was chosen to allow time for sensors to settle and so that baseline levels were determined prior to any experimental interventions. The baseline current values were matched to the post-implantation calibration data for the $\mathrm{CPE}$ (average sensitivity to oxygen $=-1.07 \mathrm{nA} / \mu \mathrm{M}$ ) and the pre-implantation calibration data for Pt/PPD/GOx (average sensitivity to glucose $=1.56 \mathrm{nA} / \mathrm{mM}$ ) as post-implantation calibration data is not available for Pt/PPD/GOx as the GOx component is lost during the explant procedure (Lowry et al., 1998c). It was determined that the basal oxygen concentration in the hippocampus is $100.26 \pm 5.76 \mu \mathrm{M}$ during the day and $99.37 \pm 5.51 \mu \mathrm{M}$ during the night. It was determined that the basal glucose concentration in the hippocampus is $0.60 \pm 0.06 \mathrm{mM}$ during the day and $0.57 \pm 0.07 \mathrm{mM}$ during the night. Paired $t$-tests revealed no significant differences between day and night for hippocampal oxygen $(t=0.3361 ; d f=9$; $p>0.05)$ or for glucose $(t=1.700 ; d f=9 ; p>0.05)$. However, it must be noted that hippocampal oxygen levels fluctuate based on activity (McHugh et al., 2011) so it is difficult to determine a true basal concentration. In the case of both oxygen and glucose, these values are given only as a guide and as such, the data in the following sections are expressed in either unconverted units (i.e. current changes; $\mathrm{nA}$ ) or as a percentage of baseline levels (i.e. normalised data; \%). 


\subsection{Effect of neuronal activation on hippocampal levels of oxygen and glucose}

Neuronal activation was induced using two different stress paradigms. Each stress paradigm was split into three time periods. The baseline period was taken as the 5 min prior to the beginning of the test, the stress period covered the $5 \mathrm{~min}$ of the actual test application and post-baseline period covered the $5 \mathrm{~min}$ following the end of the test. The data was split into $30 \mathrm{~s}$ time bins and all data were expressed as a percentage of baseline levels for comparison (Fig. 1(a) and (b)). AUC analysis was performed on the raw data to determine the mean change from the baseline signal during each of the stress paradigms (expressed in nA. min).

The tail pinch stress paradigm involved a clip being placed on the animal's tail and allowing the animal to gnaw on a piece of wood. The gnawing rather than the pressure of the clip induces global neuronal activation with an associated increase in regional cerebral blood flow, resulting in an increase in hippocampal levels of oxygen and glucose ( $n=14$ administrations in 5 animals; Fig. 1(a)). Paired $t$-tests on the data analysed via AUC showed that hippocampal oxygen significantly increased by $28.83 \mathrm{nA}$. $\min (t=2.827 ; d f=13$; $p<0.05$; Fig. 1(c)) and that hippocampal glucose also significantly increased at a rate of $0.1145 \mathrm{nA}$. $\min (t=3.023 ; d f=13 ; p<0.01$; Fig. 1(e)) during the tail pinch compared to baseline levels. Both analytes followed a similar time course following the tail pinch with hippocampal oxygen and glucose returning to baseline levels after $17.20 \pm 2.59 \mathrm{~min}$ and $17.98 \pm 2.56 \mathrm{~min}$ respectively.

The restraint stress paradigm involved manually holding the animal in place, restricting its movement. Periods of struggle are associated with an increase in neuronal activation with an associated increase in regional cerebral blood flow. As in the tail pinch stress paradigm, restraint stress resulted in an increase in hippocampal levels of oxygen and glucose ( $n=13$ administrations in 5 animals; Fig. 1(b)). Paired $t$-tests on the data analysed via AUC showed that while hippocampal oxygen significantly increased at a rate of $32.13 n$ A. $\min (t=2558 ; d f=12 ; p<0.05$; Fig. $1(d))$, the observed change in hippocampal glucose did not reach significance $(t=1.274 ; d f=12 ; p>0.05$; Fig. $1(f))$ during the restraint period compared to baseline levels. Both analytes followed a similar time course following the period of restraint with hippocampal oxygen
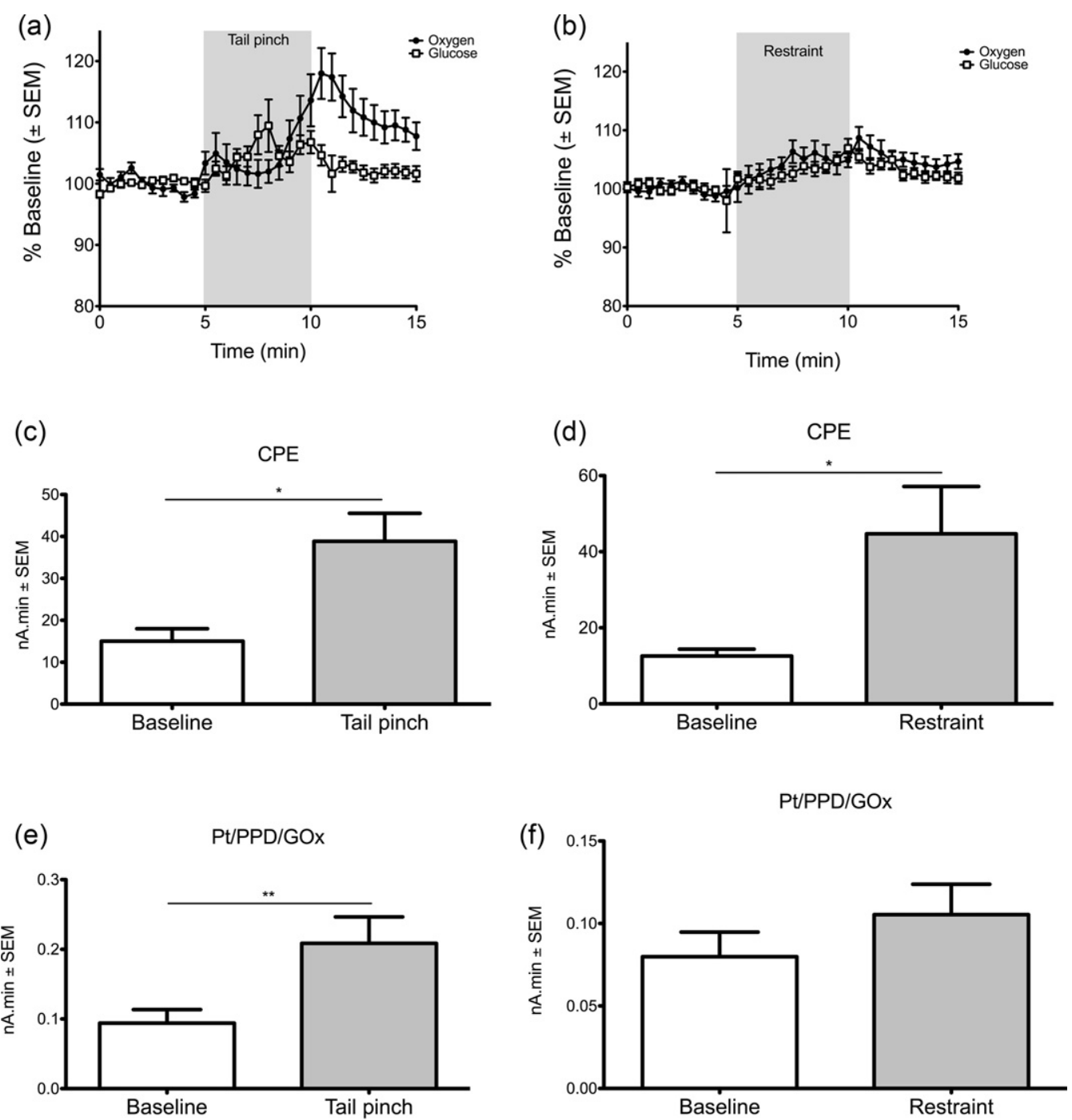

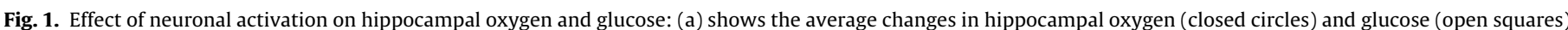

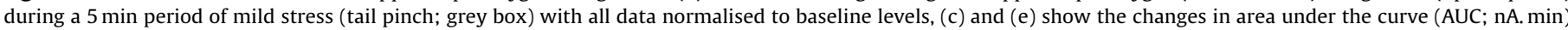

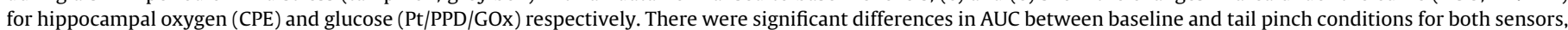

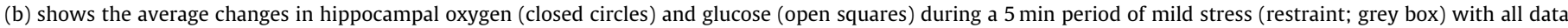

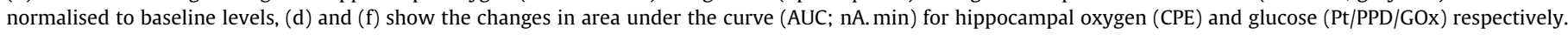
There was a significant difference in AUC between baseline and restraint conditions for the CPE alone. ${ }^{*} p<0.05 ;{ }^{* *} p<0.01$. 
and glucose returning to baseline levels after $13.42 \pm 1.97 \mathrm{~min}$ and $14.33 \pm 2.43 \mathrm{~min}$ respectively.

\subsection{Effect of mild hyperoxia and mild hypoxia on hippocampal levels of oxygen and glucose}

Animals were administered with $\mathrm{O}_{2}$ or $\mathrm{N}_{2}$ gas in order to induce short periods of mild hyperoxia or mild hypoxia respectively. This was performed in order to verify the response of the CPEs to changes in tissue levels of oxygen (Bolger and Lowry, 2005). The baseline period was taken as the $3 \mathrm{~min}$ prior to the beginning of the test, the gas administration period covered the $3 \mathrm{~min}$ of the actual test application (mild hyperoxia/hypoxia) and post-baseline period covered the $3 \mathrm{~min}$ following the end of the test. The data was split into $30 \mathrm{~s}$ time bins and all data were expressed as a percentage of baseline levels. AUC analysis was performed to determine the mean change from the baseline signal during each of the gas administrations (expressed in nA. hour).
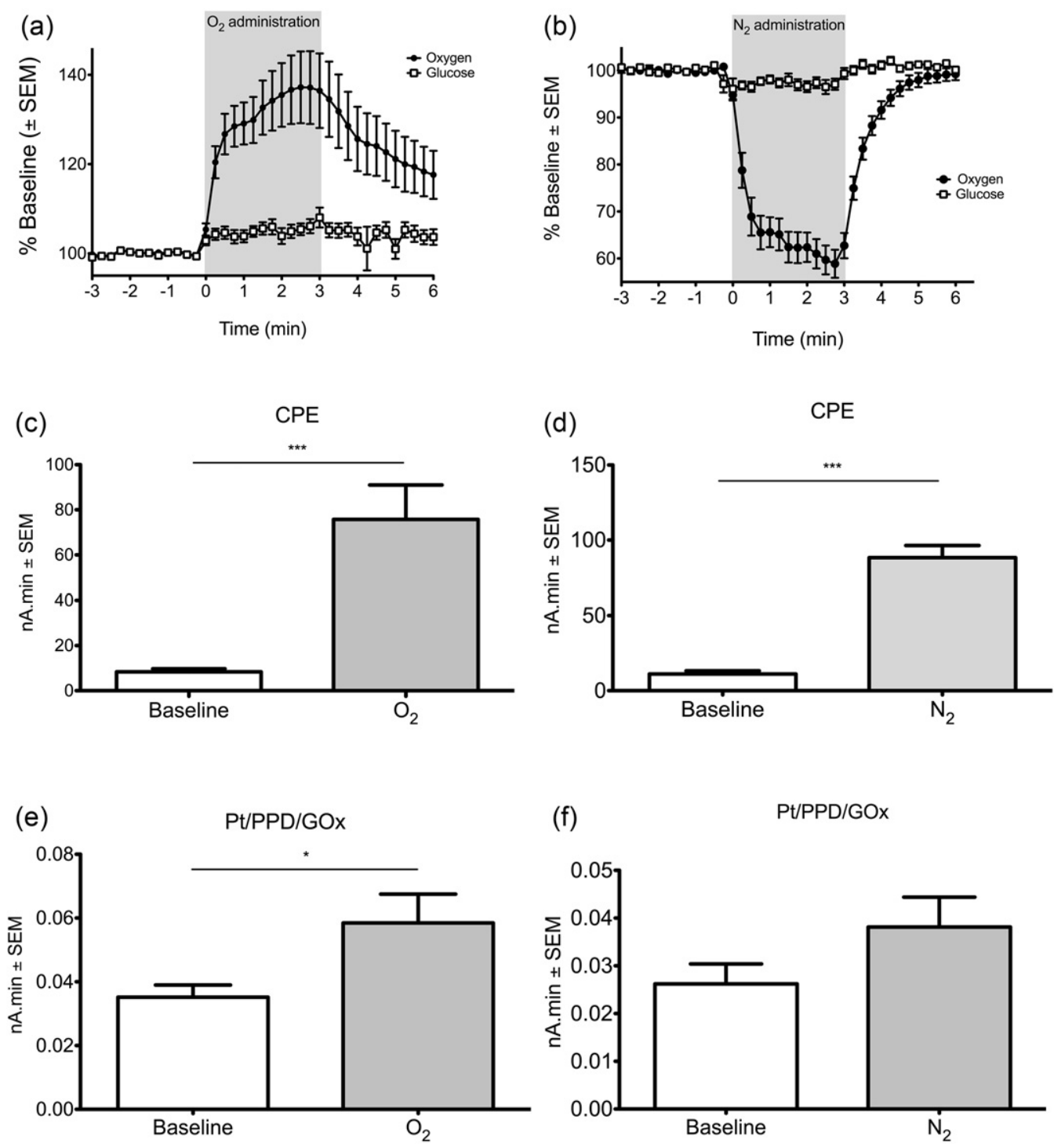

(f) Pt/PPD/GOx

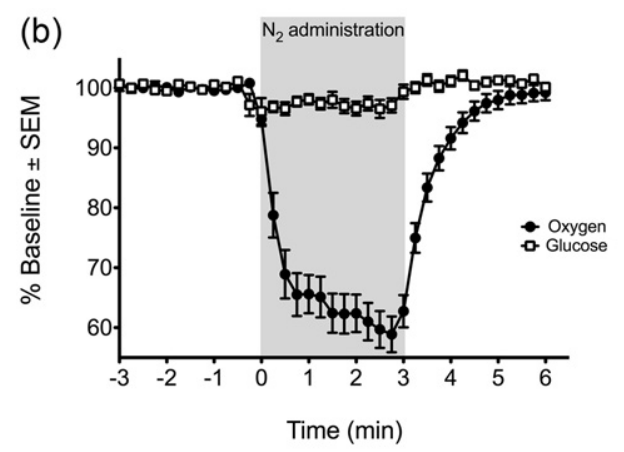
hyperoxia associated with an increase in hippocampal oxygen levels ( $n=26$ administrations in 9 animals; Fig. 2(a)). Paired $t$-tests on the data analysed via AUC showed that hippocampal oxygen significantly increased by $67.37 \mathrm{nA}$. $\min (t=4.353 ; d f=25 ; p<0.001$; Fig. 2(c)) and that hippocampal glucose also significantly increased at a rate of $0.023 \mathrm{nA}$. $\min (t=2.637 ; d f=25 ; p<0.05$; Fig. $2(\mathrm{e}))$ during administration of $\mathrm{O}_{2}$ gas compared to baseline levels. Both analytes followed a similar time course following the end of the $\mathrm{O}_{2}$ gas administration with hippocampal oxygen and glucose returning to baseline levels after $11.10 \pm 1.35 \mathrm{~min}$ and $7.01 \pm 1.25 \mathrm{~min}$ respectively.

Administration of $\mathrm{N}_{2}$ gas to the animals' snouts resulted in mild hypoxia associated with a decrease in hippocampal oxygen levels $(n=23$ administrations in 9 animals; Fig. 2(b)). Paired $t$-tests on the data analysed via AUC showed that hippocampal oxygen significantly decreased by $77.20 \mathrm{nA}$. $\min (t=9.628 ; d f=22 ; p<0.001$; Fig. 2(d)) but that there was no significant change in hippocampal glucose during the $\mathrm{N}_{2}$ gas administration $(t=2.035 ; d f=22 ; p>0.05$;

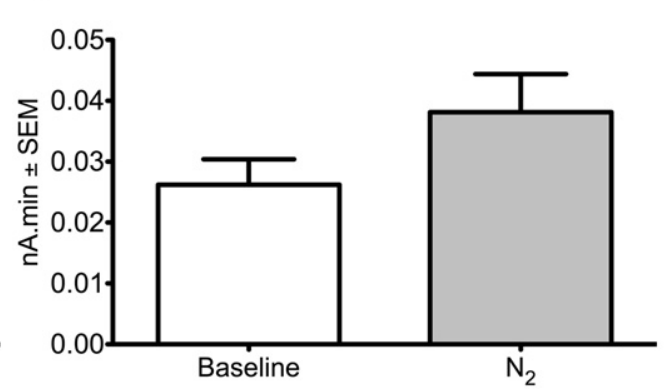

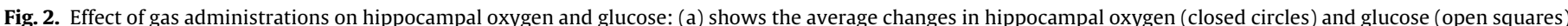

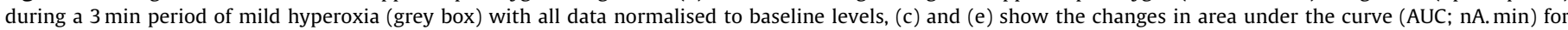

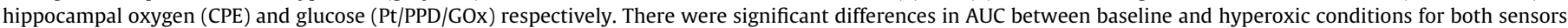

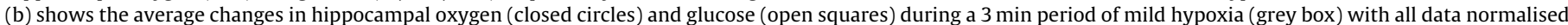

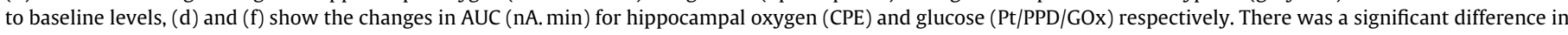
AUC between baseline and hypoxic conditions for the CPE alone. ${ }^{*} p<0.05 ;{ }^{* * *} p<0.001$. 
Fig. 2(f)) compared to baseline levels. Following the end of the $\mathrm{N}_{2}$ gas administration, hippocampal oxygen levels returned to baseline levels after $8.09 \pm 1.18 \mathrm{~min}$.

Taken together, these results verify that CPEs respond rapidly to changes in hippocampal oxygen in response to different concentrations of inhaled oxygen.

\subsection{Effect of drug treatments on hippocampal levels of oxygen and glucose}

Animals were administered with a number of different drug treatments in order to determine the effects of saline $(0.9 \%)$, chloral hydrate (350 mg/kg in saline), dimethyl sulfoxide (DMSO; 33\% in saline) and acetazolamide (Diamox ${ }^{\circledR} ; 50 \mathrm{mg} / \mathrm{kg}$ in 33\% DMSO) on hippocampal metabolism. All treatments were given via i.p. injection. The baseline period was taken as the hour prior to the injection and data was collected for $10 \mathrm{~h}$ following the injection. The data was split into $10 \mathrm{~min}$ time bins and all data were expressed as a percentage of baseline levels for visualisation and comparison. AUC analysis was performed to determine the mean change from the baseline signal during each of the drug treatment conditions (expressed in nA. hour).

Saline treatment showed no significant long-term changes in hippocampal metabolism ( $n=6$; Fig. 3(a)). A repeated-measures ANOVA on the normalised data did not reveal any significant effect for saline treatment on hippocampal oxygen when compared to baseline $(F=1.153 ; d f=10 ; 50 ; p>0.05)$. Similarly, there was no significant effect for saline treatment on hippocampal glucose $(F=1.371 ; d f=10 ; 50 ; p>0.05)$. However, there was a transient increase in hippocampal metabolism due to the injection stress. A paired $t$-test on the AUC-analysed data revealed a significant increase of $20.64 \mathrm{nA}$. hour in hippocampal oxygen following the injection compared to baseline levels $(t=3.220 ; d f=5 ; p<0.05)$ in the first 5 min post-injection. However, there was no such effect for injection stress on hippocampal glucose $(t=1.856$; $d f=5 ; p>0.05)$.

The three drug treatments all affected hippocampal metabolism when observed over several hours. The anaesthetic chloral hydrate caused significant changes in hippocampal metabolism $(n=8$; Fig. 3(b)). A repeated-measures ANOVA on the normalised data revealed that chloral hydrate treatment had a significant effect on hippocampal oxygen when compared to baseline $(F=12.98$; $d f=10 ; 70 ; p<0.001)$ and a $2 \times 11$ mixed factorial ANOVA with treatment (saline; chloral hydrate) as a between subject variable and time (baseline and hours 1-10 post-injection) as a within subject variable on the normalised data showed that there was no overall significant effect for treatment when compared to the saline-treated group $(F=3.539 ; d f=1,120 ; p>0.05)$. However, there was a significant effect for time $(F=9.661 ; d f=10,120$; $p<0.001)$ and a significant interaction effect $(F=7.121 ; d f=10,120$; $p<0.001)$. Compared to saline injections at the same time points (i.e. $0-3 \mathrm{~h}$ post-injection), an unpaired $t$-test on the AUC-analysed data revealed that there was a significant increase in hippocampal oxygen of $65.36 \pm 18.33 \mathrm{nA}$. hour compared to baseline $(t=3.565$; $\mathrm{df}=13 ; p<0.01$; Fig. 4(a)).

A repeated-measures ANOVA on the normalised data revealed that chloral hydrate treatment had a significant effect on hippocampal glucose when compared to baseline $(F=4.696 ; d f=10$; $70 ; p<0.001)$ and a $2 \times 11$ mixed factorial ANOVA with treatment (saline; chloral hydrate) as a between subject variable and time (baseline and hours 1-10 post-injection) as a within subject variable on the normalised data showed that there was a significant effect for treatment $(F=4.894 ; d f=1,120 ; p<0.05)$, a significant
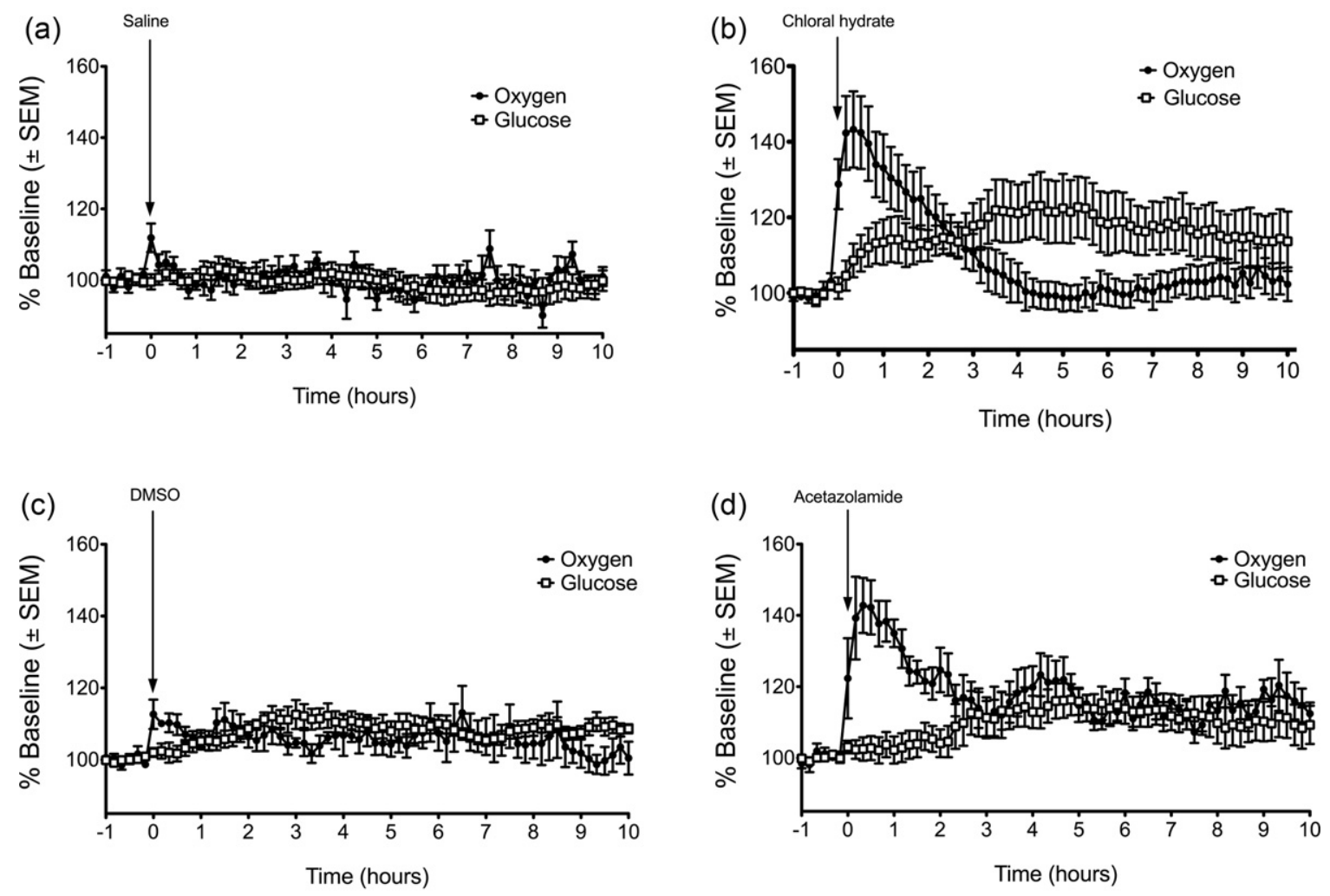

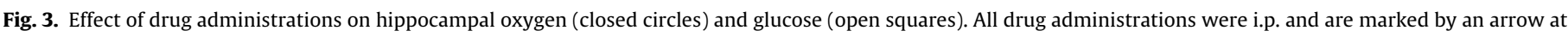

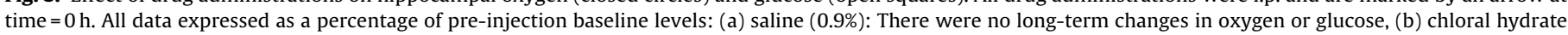

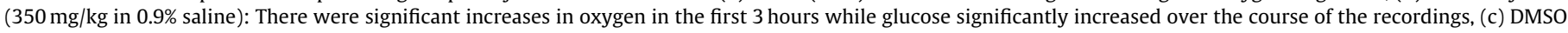

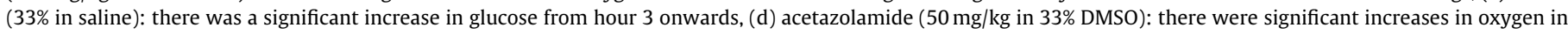
the first $5 \mathrm{~h}$ and from hours $4-8$ there was a significant increase in glucose. 
(a)

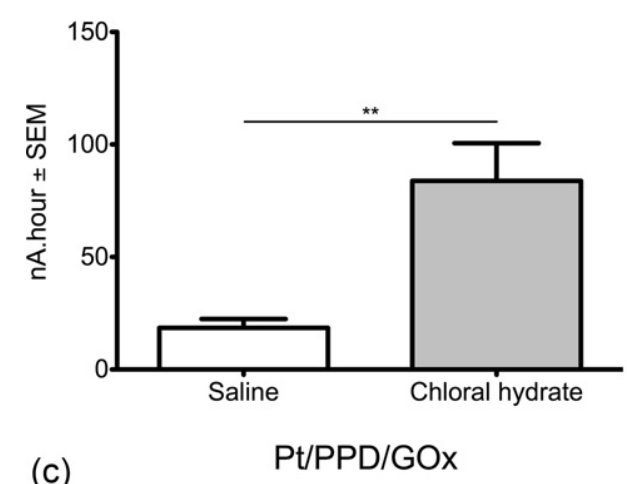

(c)

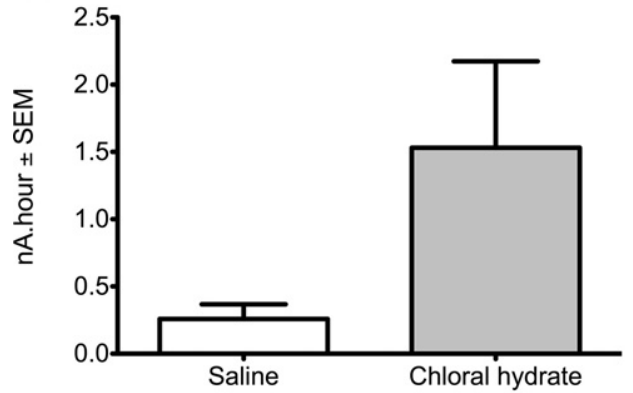

(b)

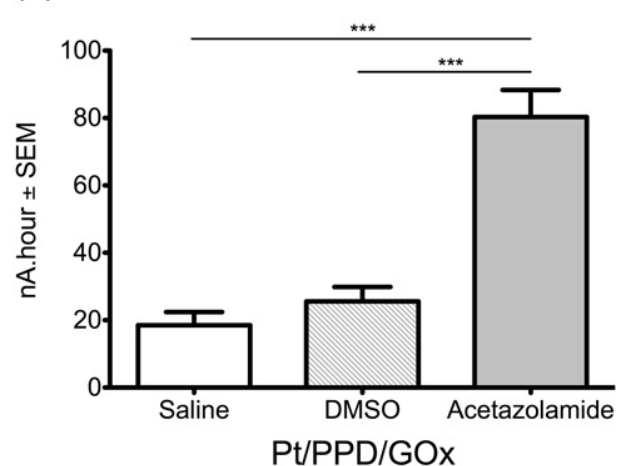

(d)

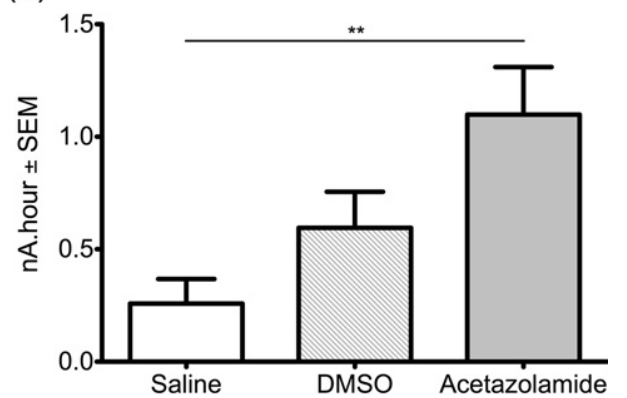

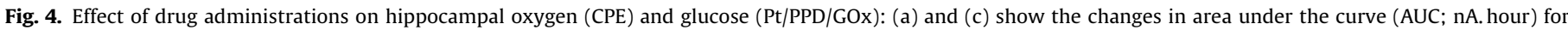

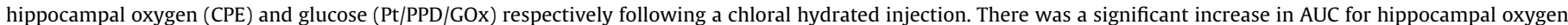

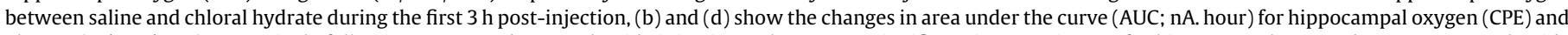

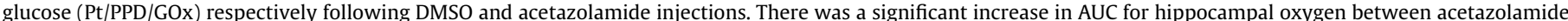

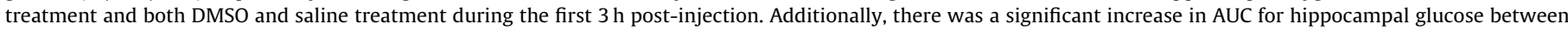
acetazolamide treatment and saline treatment. ${ }^{* *} p<0.01$; ${ }^{* * *} p<0.001$.

effect for time $(F=2.964 ; d f=10,120 ; p<0.01)$ and a significant interaction effect $(F=3.512 ; d f=10,120 ; p<0.001)$. An unpaired $t$-test on the AUC-analysed data revealed that there was a nonsignificant increase of $1.12 \pm 0.68 \mathrm{nA}$. hour in hippocampal glucose $(0-10 \mathrm{~h}$ post-injection) compared to baseline $(t=1.801 ; \mathrm{df}=11$; $p>0.05$; Fig. 4(c)).

As acetazolamide does not dissolve easily in saline, a 33\% solution of DMSO was used as a vehicle. Animals were treated with 33\% DMSO in order to act as a control for acetazolamide treatment. It was found that DMSO alone had a significant effect on hippocampal metabolism ( $n=6$; Fig. 3(c)). While a repeated-measures ANOVA on the normalised data revealed that DMSO treatment had a significant effect on hippocampal oxygen $(F=2.124 ; d f=10 ; 50 ; p<0.05)$ and on hippocampal glucose $(F=5.330 ; d f=10 ; 50 ; p<0.001)$ when compared to baseline. Acetazolamide treatment was also shown to have a significant effect on hippocampal metabolism $(n=6$; Fig. 3(d)). A repeated-measures ANOVA on the normalised data revealed that acetazolamide treatment had a significant effect on hippocampal oxygen $(F=7.626 ; d f=10 ; 50 ; p<0.001)$ and on hippocampal glucose $(F=4.698 ; d f=10 ; 50 ; p<0.001)$ when compared to baseline.

Comparing the effects of saline-, DMSO- and acetazolamidetreated animals on hippocampal oxygen, a $3 \times 11$ mixed factorial ANOVA with treatment (saline; DMSO; acetazolamide) as a between subject variable and time (baseline and hours 1-10 postinjection) as a within subject variable on the normalised data showed that there was a significant effect for treatment $(F=11.82$; $d f=2,15 ; p<0.001)$, time $(F=7.90 ; d f=10,150 ; p<0.001)$ as well as an interaction effect $(F=3.69 ; d f=20,150 ; p<0.001)$. Compared to saline injections at the same time points (i.e. $0-3 \mathrm{~h}$ post-injection), a one-way ANOVA on the AUC-analysed data showed that there was a significant effect for drug treatment on hippocampal oxygen
$(F=36.46 ; d f=2,16 ; p<0.001$; Fig. 4(b)). Bonferroni post hoc analysis revealed that while there was no significant difference between saline- and DMSO-treated animals $(p>0.05)$, acetazolamide did have a significant effect on hippocampal oxygen. Acetazolamide treatment significantly increase hippocampal oxygen by $61.80 \mathrm{nA}$. hour compared to saline-treated animals $(p<0.001)$ and by $54.71 \mathrm{nA}$. hour compared to DMSO-treated animals $(p<0.001)$.

Comparing the effects of saline-, DMSO- and acetazolamidetreated animals on hippocampal glucose, a $3 \times 11$ mixed factorial ANOVA on the normalised data showed that there was a significant effect for treatment $(F=3.75 ; d f=2,15 ; p<0.05)$, time $(F=6.05$; $d f=10,150 ; p<0.001)$ as well as an interaction effect $(F=3.00$; $d f=20,150 ; p<0.001)$. Compared to saline injections, a one-way ANOVA on the AUC-analysed data showed that there was a significant effect for drug treatment on hippocampal glucose $(F=6.679$; $d f=2 ; 14 ; p<0.01 ;$ Fig. $4(d))$. Bonferroni post hoc analysis revealed that while there was no significant difference between salineand DMSO-treated animals $(p>0.05)$, acetazolamide did have a significant effect on hippocampal glucose. Acetazolamide treatment significantly increase hippocampal glucose by $0.840 \mathrm{nA}$. hour compared to saline-treated animals $(p<0.001)$ but there was no significant difference between acetazolamide- and DMSO-treated animals $(p>0.05)$.

\section{Discussion}

While CPEs have been previously used to measure hippocampal oxygen during various behavioural tasks (McHugh et al., 2011), this is the first full characterisation of hippocampal metabolism to be published using these sensors. Additionally, by co-implanting a $\mathrm{CPE}$ and Pt/PPD/GOx biosensor in the same region of the hippocampus, we have also been able to demonstrate that the temporal 
relationships between hippocampal oxygen and glucose levels vary during a number of different conditions. Here, we demonstrate that neuronal activation (increased during stress paradigms and decreased during anaesthesia) can alter levels of hippocampal oxygen and glucose. Furthermore, pharmacological interventions can be monitored for hours using these sensors on a subsecond scale.

There have been few studies utilising sensors to measure hippocampal glucose as most research groups tend to employ microdialysis. Most studies report much higher concentrations of glucose in the hippocampus compared to the value reported above $(0.60 \pm 0.06 \mathrm{mM})$; one study using a glucose biosensor puts the concentration as high as $2.6 \pm 0.2 \mathrm{mM}$ in anaesthetised rats (Hu and Wilson, 1997). However, a number of studies utilising microdialysis in freely-moving rats have suggested that the basal hippocampal glucose concentration is somewhere between 1 and $1.5 \mathrm{mM} ; 1.00 \pm 0.06 \mathrm{mM}$ (McNay and Gold, 1999), $1.2 \pm 0.03 \mathrm{mM}$ (McNay et al., 2000), $1.05 \pm 0.02 \mathrm{mM}$ (McNay and Sherwin, 2004b), $1.49 \pm 0.05 \mathrm{mM}$ (Rex et al., 2009) and $1.36 \pm 0.04 \mathrm{mM}$ (de Bundel et al., 2009) all being representative examples of such findings.

Moreover, these microdialysis studies utilise a zero net flux model of measuring glucose and there has been criticism of the use of this method to determine basal concentrations of analytes in the brain due to variability in the perfusate being used by different groups (McNay and Sherwin, 2004a) and the trauma caused by the implantation of the microdialysis probe (Chen, 2003, 2005a, 2005b, 2006). These criticisms are reinforced by the disparity observed between sensor recordings and microdialysis analysis due to the trauma caused by the much larger microdialysis probe (Khan and Michael, 2003). It has been reported that dopamine microsensors implanted directly adjacent to microdialysis probes are unable to detect the release of dopamine whereas microsensors implanted $1 \mathrm{~mm}$ away from the probe are unaffected (Yang et al., 1998). Furthermore, our more modest estimate of $0.60 \pm 0.06 \mathrm{mM}$ may also be artificially lower than actual concentrations as it has been shown that enzyme-based sensors have a tendency to lose $20-50 \%$ sensitivity when implanted into the brain (Hu et al., 1994). Taken together, we predict that the basal glucose concentration in the hippocampus is somewhere between our estimate and those of the microdialysis studies referenced above.

While previous work in the hippocampus has reported changes in oxygen concentration, we believe this is the first report to determine the in vivo basal concentration of hippocampal oxygen in the freely-moving rat. In comparison, the oxygen levels found in the hippocampus $(100.26 \pm 5.76 \mu \mathrm{M})$ in this study are quite high with hippocampal oxygen being $33.6 \mathrm{~mm} \mathrm{Hg}(\sim 52.8 \mu \mathrm{M})$ in the anaesthetised gerbil (Nair et al., 1987) and $20.3 \mathrm{~mm} \mathrm{Hg}(\sim 31.9 \mu \mathrm{M})$ in the anaesthetised rat (Cater et al., 1961). Compared to other regions in the rat brain, the hippocampal oxygen levels found here also appear to be higher with $50 \mu \mathrm{M}$ in the caudate nucleus (Zimmerman and Wightman, 1991) and $37 \pm 16 \mu \mathrm{M}$ (Bazzu et al., 2009) or $33 \pm 14 \mu \mathrm{M}$ (Calia et al., 2009) in the striatum.

However, our estimates of the basal concentration of oxygen in the hippocampus are given only as a guide as basal concentrations of any measure of neural activity are difficult to establish. Firstly, it is hard to objectively determine what constitutes a baseline level of activity when considering the normal functions of a specific brain region. Secondly, overall changes in regional cerebral blood flow could impact on the oxygen levels even when a brain region of interest is "inactive". Oxygen levels fluctuate considerably even across short time scales with locomotor activity being an obvious influence on hippocampal oxygen even when not engaged in a hippocampus-dependent task (McHugh et al., 2011). As it has previously been shown that oxygen measured using amperometric sensors is directly comparable to the BOLD signal in fMRI (Lowry et al., 2010; Francois et al., 2012), these fluctuations may also be due to changes in synaptic activity in a given region of the brain
(Logothetis et al., 2001; Goense and Logothetis, 2008; Li et al., 2011). Therefore, these concentrations are given only as preliminary estimates and the main findings of these experiments are expressed as changes away from the baseline rather than absolute changes in concentration as we would expect the direction and extent of these changes to be similar to those found with other sampling methods.

Using CPEs with CPA in the striatum, the tail pinch stress paradigm is associated with an increase in oxygen levels, which returns to baseline after the removal of the tail clip (Lowry and Fillenz, 1997). This increase and return to baseline in the striatum has been replicated using CPEs with differential pulse amperometry (Bolger and Lowry, 2005) and a graphite-based conical oxygen sensor with CPA (Bazzu et al., 2009). Lowry and Fillenz (1997) also found that there was a decrease in striatal glucose measured using a Pt/PPD/GOx biosensor during the tail pinch and that following the removal of the tail clip, glucose levels increased higher than baseline levels. This effect of the tail pinch on striatal glucose has also been found using microdialysis (Fray et al., 1996). While we found that both hippocampal oxygen and glucose levels changed in response to the tail pinch stress paradigm, our data did not mirror the findings in the striatum as we observed an overshoot in hippocampal oxygen after the removal of the clip whereas glucose rapidly returned to baseline (the opposite to the striatum). As hippocampal oxygen increased immediately after removal of the tail clip, this indicates that during the tail pinch oxygen supply was approximately balanced with utilisation. On the other hand, hippocampal glucose did increase significantly during the tail pinch but rapidly returned to baseline following the removal of the tail clip. So although there is increased supply of oxygen in the striatum during the tail pinch, there is not increased utilisation of oxygen, thus leading to an overall increase in the oxygen concentration in the striatum. In contrast, it appears there is an increase in supply of hippocampal oxygen with a concurrent increase in its utilisation during the tail pinch paradigm. Evidence for this comes from the finding that when the tail clip is removed, the utilisation of hippocampal oxygen decreases (as neuronal activation should decrease) but supply remains high for several minutes following the test, perhaps reflecting an increase in regional cerebral blood flow due to increased activity by the animal in the bowl following the removal of the tail clip. This increase may be due to increased locomotor activity which has been shown previously to be closely correlated to increases in the hippocampal oxygen signal (McHugh et al., 2011).

In the case of hippocampal glucose, there seems to be an increase in its supply but not its utilisation (as tissue levels increased during neuronal activation), reflecting an alternative use for glucose during this form of neuronal activation compared to the situation in the striatum. Differences in how tail pinch stress affects the striatum and the hippocampus are not to be unexpected as neuronal activation from tail pinch stress has been shown to increase striatal dopamine and ascorbic acid compared with 5-hydroxytryptamine and 5-hydroxyindole acetic acid in the hippocampus (Boutelle et al., 1990), perhaps reflecting different mechanisms and different roles for the two regions.

The effect of acetazolamide on oxygen levels has been previously demonstrated in the striatum using CPEs with differential pulse amperometry (Dixon et al., 2002; Bolger and Lowry, 2005) and a graphite-based conical oxygen sensor (Bazzu et al., 2009) where administration of acetazolamide results in increased striatal oxygen levels lasting for several hours. Bolger and Lowry (2005) also demonstrated that the increase in striatal oxygen was correlated with regional cerebral blood flow. Here, we found a similar effect for acetazolamide on hippocampal oxygen; administration of acetazolamide causes a rapid increase in hippocampal oxygen lasting for several hours. 
However, due to the difficulty in forming an acetazolamide solution in saline we used a high concentration of DMSO in order to administer the drug. Analysis on the normalised data suggests that DMSO treatment resulted in a significant increase in hippocampal glucose levels beginning about $3 \mathrm{~h}$ after the injection and this result was also found following acetazolamide treatment. As acetazolamide treatment in the absence of DMSO is not associated with any changes in striatal glucose (Dixon et al., 2002), this suggests that in this study that acetazolamide treatment itself has no effect on hippocampal glucose but the DMSO used as the vehicle does. At the very least, there may be an interaction between the DMSO and acetazolamide as the AUC analysis showed that acetazolamide treatment significantly increase hippocampal glucose levels. The effects of DMSO on brain metabolism has been implied for several years; early work indicated that the application of DMSO to brain slices increases glucose consumption (Ghosh et al., 1976) and in vitro administration of DMSO appears to cause more varied dose-dependent effects on glucose metabolism in brain slices from guinea pigs (Nasrallah et al., 2008). Comparing our results to those of these other groups creates a complex picture with low concentrations of DMSO administered directly to brain tissue causing rapid changes in glucose metabolism in contrast to our findings where high concentrations of DMSO administered intraperitoneally caused a delayed but long-lasting increase in glucose concentration, perhaps reflecting a decrease in glucose consumption over longer time periods.

The suppression of neural activity by anaesthesia and its effects on glucose in the brain has been previously demonstrated using a number of different anaesthetic agents, including chloral hydrate (Fellows et al., 1992; Fillenz and Lowry, 1998b; Lowry et al., 1998a; Lowry and Fillenz, 2001; Uematsu et al., 2009; Horn and Klein, 2010). Our data for hippocampal oxygen follows the same patterns observed in the striatum during chloral hydrate anaesthesia, namely an increase in tissue levels of oxygen during the period of anaesthesia with a return to baseline levels following the return to consciousness (Bolger and Lowry, 2005). This increase in oxygen is associated with a decrease in neuronal activation and an increase in regional cerebral blood flow (Lowry et al., 1998a; Lowry and Fillenz, 2001). The anaesthesia-induced increase in hippocampal glucose observed here in the normalised data analysis is in agreement with microdialysis data from the hippocampus (Horn and Klein, 2010) and the striatum (Fellows et al., 1992), radioactive tracing experiments in the cortex (McDougal et al., 1990) and glucose biosensors in the cortex (Netchiporouk et al., 2001). However, this change in hippocampal glucose was not reflected in the AUC analysis. Bearing in mind that conflicting results have also been reported using electrochemical detection methods in the striatum where chloral hydrate administration has been associated with a decrease in tissue glucose (Fillenz and Lowry, 1998b; Lowry and Fillenz, 2001). Yet, it would be expected that a decrease in neuronal activity should result in an increase in tissue glucose due to decreased utilisation. Support for this comes from the growing body of evidence to suggest that the brain switches between glucose and lactate under different levels of activity (Dienel and Hertz, 2001). The utilisation of glucose by the brain has been suggested to be dependent on neuronal activity (Serres et al., 2005) and it has been shown that there is increased utilisation of lactate during chloral hydrate anaesthesia, suggesting that the brain switches to lactate as an energy source during this (Yamada et al., 2009) and other anaesthetic conditions (Serres et al., 2004; Horn and Klein, 2010).

The use of these sensors is not restricted to acute pharmacological studies; CPEs have been used to show differential activity in the dorsal and ventral regions of the hippocampus during spatial and anxiety components of a radial arm maze task (McHugh et al., 2011). Further unpublished data from our lab shows that hippocampal activity measured using CPEs and Pt/PPD/GOx biosensors can be used to compare different behaviours in a +-maze task. This form of data acquisition during behavioural tasks can be coupled with drug interventions and the changes observed can be compared directly to more traditional methods such as electrophysiological recordings and microdialysis sampling.

\section{Acknowledgements}

The authors would like to thank Dr. Fiachra Bolger and Dr. Niall Finnerty for their suggestions and advice on this project. This research was made possible by funding provided by Enterprise Ireland (PC/2009/523 and CP/2011/0103), NUI Maynooth (John and Pat Hume Scholarship) and the Centre of Applied Science for Health which is funded by the Higher Education Authority under the Programme for Research in Third Level Institutions (PRTLI) Cycle 4.

\section{Appendix A. Supplementary data}

Supplementary data associated with this article can be found, in the online version, at http://dx.doi.org/10.1016/j.jneumeth. 2013.02.016.

\section{References}

Andrews PJ, Dearden NM, Miller JD. Jugular bulb cannulation: description of a cannulation technique and validation of a new continuous monitor. $\mathrm{Br} \mathrm{J}$ Anaesth 1991;67:553-8

Antelman SM, Szechtman H, Chin P, Fisher AE. Tail pinch-induced eating, gnawing and licking behavior in rats: dependence on the nigrostriatal dopamine system. Brain Res 1975;99:319-37.

Barry DN, Commins S. Imaging spatial learning in the brain using immediate early genes: insights, opportunities and limitations. Rev Neurosci 2011;22:131-242.

Bast T. The hippocampal learning-behavior translation and the functional significance of hippocampal dysfunction in schizophrenia. Curr Opin Neurobiol 2011;21:492-501.

Bazzu G, Puggioni GG, Dedola S, Calia G, Rocchitta G, Migheli R, et al. Real-time monitoring of brain tissue oxygen using a miniaturized biotelemetric device implanted in freely moving rats. Anal Chem 2009;81:2235-41.

Bliss TV, Lomo T. Long-lasting potentiation of synaptic transmission in the dentate area of the anaesthetized rabbit following stimulation of the perforant path. J Physiol 1973;232:331-56.

Bolger FB, Lowry JP. Brain tissue oxygen: in vivo monitoring with carbon paste electrodes. Sensors 2005;5:473-87.

Bolger FB, Bennett R, Lowry JP. An in vitro characterisation comparing carbon paste and Pt microelectrodes for real-time detection of brain tissue oxygen. Analyst 2011a;136:4028-35.

Bolger FB, McHugh SB, Bennett R, Li J, Ishiwari K, Francois J, et al. Characterisation of carbon paste electrodes for real-time amperometric monitoring of brain tissue oxygen. J Neurosci Methods 2011b;195:135-42.

Bonilha L, Martz GU, Glazier SS, Edwards JC. Subtypes of medial temporal lobe epilepsy: influence on temporal lobectomy outcomes? Epilepsia 2012;53:1-6.

Borland LM, Shi G, Yang H, Michael AC. Voltammetric study of extracellular dopamine near microdialysis probes acutely implanted in the striatum of the anesthetized rat. J Neurosci Methods 2005;146:149-58.

Bourdillon C, Thomas V, Thomas D. Electrochemical study of D-glucose oxidase autoinactivation. Enzyme Microb Technol 1982;4:175-80.

Boutelle MG, Stanford C, Fillenz M, Albery WJ, Bartlett PN. An amperometric enzyme electrode for monitoring brain glucose in the freely moving rat. Neurosci Lett 1986;72:283-8

Boutelle MG, Zetterström T, Pei Q, Svensson L, Fillenz M. In vivo neurochemica effects of tail pinch. J Neurosci Methods 1990;34:151-7.

Brown FO, Finnerty NJ, Lowry JP. Nitric oxide monitoring in brain extracellular fluid: characterisation of Nafion-modified Pt electrodes in vitro and in vivo. Analys 2009;134:2012-20.

Bungay PM, Newton-Vinson P, Isele W, Garris PA, Justice JB. Microdialysis of dopamine interpreted with quantitative model incorporating probe implantation trauma. J Neurochem 2003;86:932-46.

Calia G, Rocchitta G, Migheli R, Puggioni G, Spissu Y, Bazzu G, et al. Biotelemetric monitoring of brain neurochemistry in conscious rats using microsensors and biosensors. Sensors (Basel) 2009;9:2511-23.

Cater DB, Garattini S, Marina F, Silver IA. Changes of oxygen tension in brain and somatic tissues induced by vasodilator and vasoconstrictor drugs. Proc R Soc Lond B 1961;155:136-58.

Chen KC. Insensitivity of the microdialysis zero-net-flux method to nonlinear uptake and release processes. Neurosci Res 2003;46:251-6.

Chen KC. Preferentially impaired neurotransmitter release sites not their discreteness compromise the validity of microdialysis zero-net-flux method. J Neurochem 2005a;92:29-45. 
Chen KC. Evidence on extracellular dopamine level in rat striatum: implications for the validity of quantitative microdialysis. J Neurochem 2005b;92: 46-58.

Chen KC. Effects of tissue trauma on the characteristics of microdialysis zero-net-flux method sampling neurotransmitters. J Theor Biol 2006;238:863-81.

Choi IY, Lee SP, Kim SG, Gruetter R. In vivo measurements of brain glucose transport using the reversible Michaelis-Menten model and simultaneous measurements of cerebral blood flow changes during hypoglycemia. J Cereb Blood Flow Metab 2001;21:653-63.

Clark Jr LC, Misrahy G, Fox RP. Chronically implanted polarographic electrodes. J Appl Physiol 1958;13:85-91.

Cloutier M, Bolger FB, Lowry JP, Wellstead P. An integrative dynamic model of brain energy metabolism using in vivo neurochemical measurements. J Comput Neurosci 2009;27:391-414.

Cohen NJ, Ryan J, Hunt C, Romine L, Wszalek T, Nash C. Hippocampal system and declarative (relational) memory: summarizing the data from functional neuroimaging studies. Hippocampus 1999;9:83-98.

Colgin LL, Moser EI. Gamma oscillations in the hippocampus. Physiology (Bethesda) 2010;25:319-29.

De Bundel D, Smolders I, Yang R, Albiston AL, Michotte Y, Chai SY. Angiotensin IV and LVV-haemorphin 7 enhance spatial working memory in rats: effects on hippocampal glucose levels and blood flow. Neurobiol Learn Mem 2009;92: 19-26.

De Deyne C, Van Aken J, Decruyenaere J, Struys M, Colardyn F. Jugular bulb oximetry: review on a cerebral monitoring technique. Acta Anaesthesiol Belg 1998;49:21-31.

Dhikav V, Anand K. Potential predictors of hippocampal atrophy in Alzheimer's disease. Drugs Aging 2011;28:1-11.

D'Hooge R, De Deyn PP. Applications of the Morris water maze in the study of learning and memory. Brain Res Rev 2001;36:60-90.

Dienel GA, Hertz L. Glucose and lactate metabolism during brain activation. J Neurosci Res 2001;66:824-38.

Dixon BM, Lowry JP, O'Neill RD. Characterization in vitro and in vivo of the oxygen dependence of an enzyme/polymer biosensor for monitoring brain glucose. J Neurosci Methods 2002;119:135-42.

Doppenberg EM, Zauner A, Bullock R, Ward JD, Fatouros PP, Young HF. Correlations between brain tissue oxygen tension, carbon dioxide tension, $\mathrm{pH}$, and cerebral blood flow-a better way of monitoring the severely injured brain? Surg Neurol 1998;49:650-4.

Eacott MJ, Easton A. Episodic memory in animals: remembering which occasion. Neuropsychologia 2011;48:2273-80.

Feldman Z, Robertson CS. Monitoring of cerebral hemodynamics with jugular bulb catheters. Crit Care Clin 1997;13:51-77.

Fellows LK, Boutelle MG, Fillenz M. Extracellular brain glucose levels reflect local neuronal activity: a microdialysis study in awake, freely moving rats. J Neurochem 1992:59:2141-7.

Fillenz M, Lowry JP. Studies of the source of glucose in the extracellular compartment of the rat brain. Dev Neurosci 1998a;20:365-8.

Fillenz M, Lowry JP. The relation between local cerebral blood flow and extracellular glucose concentration in rat striatum. Exp Physiol 1998b;83:233-8.

Finnerty NJ, O'Riordan SL, Palsson E, Lowry JP. Brain nitric oxide: regional characterisation of a real-time microelectrochemical sensor. J Neurosci Methods 2012;209:13-21.

Foster TH, Hartley DF, Nichols MG, Hilf R. Fluence rate effects in photodynamic therapy of multicell tumor spheroids. Cancer Res 1993;53:1249-54.

Francois J, Conway MW, Lowry JP, Tricklebank MD, Gilmour G. Changes in rewardrelated signals in the rat nucleus accumbens measured by in vivo oxygen amperometry are consistent with fMRI BOLD responses in man. Neuroimage 2012;60:2169-81.

Fray AE, Forsyth RJ, Boutelle MG, Fillenz M. The mechanisms controlling physiologically stimulated changes in rat brain glucose and lactate: a microdialysis study. J Physiol 1996;496:49-57.

Freund TF, Buzsáki G, Prohaska OJ, Leon A, Somogyi P. Simultaneous recording of local electrical activity, partial oxygen tension and temperature in the rat hippocampus with a chamber-type microelectrode. Effects of anaesthesia, ischemia and epilepsy. Neuroscience 1989;28:539-49.

Geise RJ, Adams JM, Barone NJ, Yacynych AM. Electropolymerized films to prevent interferences and electrode fouling in biosensors. Biosens Bioelectron 1991;6:151-60.

Ghosh AK, Tatsuji I, Ghosh S, Sloviter HA. Effects of dimethylsulfoxide on metabolism of isolated perfused rat brain. Biochem Pharmacol 1976;25:1115-7.

Glover GH. Overview of functional magnetic resonance imaging. Neurosurg Clin N Am 2011;22:133-9.

Goense JB, Logothetis NK. Neurophysiology of the Bold fMRI signal in awake monkeys. Curr Biol 2008;18:631-40.

Gold PE. Acetylcholine modulation of neural systems involved in learning and memory. Neurobiol Learn Mem 2003;80:194-210.

Gooney M, Shaw K, Kelly A, O'Mara SM, Lynch MA. Long-term potentiation and spatial learning are associated with increased phosphorylation of TrkB and extracellular signal-regulated kinase (ERK) in the dentate gyrus: evidence for a role for brain-derived neurotrophic factor. Behav Neurosci 2002;116: 455-63.

Gupta AK, Hutchinson PJ, Al-Rawi P, Gupta S, Swart M, Kirkpatrick PJ, Menon DK, Datta AK. Measuring brain tissue oxygenation compared with jugular venous oxygen saturation for monitoring cerebral oxygenation after traumatic brain injury. Anesth Analg 1999;88:549-53.
Heckers S, Konradi C. Hippocampal pathology in schizophrenia. Curr Top Behav Neurosci 2010;4:529-53.

Horn T, Klein J. Lactate levels in the brain are elevated upon exposure to volatile anesthetics: a microdialysis study. Neurochem Int 2010;57:940-7.

Hu Y, Mitchell KM, Albahadily FN, Michaelis EK, Wilson GS. Direct measurement of glutamate release in the brain using a dual enzyme-based electrochemical sensor. Brain Res 1994;659:117-25.

Hu Y, Wilson GS. Rapid changes in local extracellular rat brain glucose observed with an in vivo glucose sensor. J Neurochem 1997;68:1745-52.

Khan AS, Michael AC. Invasive consequences of using micro-electrodes and microdialysis probes in the brain. Trends Anal Chem 2003;22:503-8.

Krolicki L, Leniger-Follert E. Oxygen supply of the brain cortex (rat) during severe hypoglycemia. Pflugers Arch 1980;387:121-6.

Kulagina NV, Shankar L, Michael AC. Monitoring glutamate and ascorbate in the extracellular space of brain tissue with electrochemical microsensors. Anal Chem 1999;71:5093-100.

Li J, Bravo DS, Upton AL, Gilmour G, Tricklebank MD, Fillenz M, et al. Close temporal coupling of neuronal activity and tissue oxygen responses in rodent whisker barrel cortex. Eur J Neurosci 2011;34:1983-96.

Logothetis NK, Pauls J, Augath M, Trinath T, Oeltermann A. Neurophysiological investigation of the basis of the fMRI signal. Nature 2001;412:150-7.

López-Pérez SJ, Morales-Villagrán A, Ventura-Valenzuela J, Medina-Ceja L. Shortand long-term changes in extracellular glutamate and acetylcholine concentrations in the rat hippocampus following hypoxia. Neurochem Int 2012;61:258-65.

Lowry JP, McAteer K, El Atrash SS, Duff A, O'Neill RD. Characterization of glucose oxidase-modified poly(phenylenediamine)-coated electrodes in vitro and in vivo: homogeneous interference by ascorbic acid in hydrogen peroxide detection. Anal Chem 1994;66:1754-61.

Lowry JP, O'Neill RD. Partial characterization in vitro of glucose oxidase-modified poly(phenylenediamine)-coated electrodes for neurochemical analysis in vivo. Electroanalysis 1994;6:369-79.

Lowry JP, Boutelle MG, O'Neill RD, Fillenz M. Characterization of carbon paste electrodes in vitro for simultaneous amperometric measurement of changes in oxygen and ascorbic acid concentrations in vivo. Analyst 1996;121: 761-6.

Lowry JP, Boutelle MG, Fillenz M. Measurement of brain tissue oxygen at a carbon past electrode can serve as an index of increases in regional cerebral blood flow. J Neurosci Methods 1997;71:177-82.

Lowry JP, Fillenz M. Evidence for uncoupling of oxygen and glucose utilization during neuronal activation in rat striatum. J Physiol 1997;498:497-501.

Lowry JP, Demestre M, Fillenz M. Relation between cerebral blood flow and extracellular glucose in rat striatum during mild hypoxia and hyperoxia. Dev Neurosci 1998a;20:52-8.

Lowry JP, Miele M, O'Neill RD, Boutelle MG, Fillenz M. An amperometric glucoseoxidase/poly(o-phenylenediamine) biosensor for monitoring brain extracellular glucose: in vivo characterisation in the striatum of freely-moving rats. J Neurosci Methods 1998b;79:65-74.

Lowry JP, O'Neill RD, Boutelle MG, Fillenz M. Continuous monitoring of extracellular glucose concentrations in the striatum of freely moving rats with an implanted glucose biosensor. J Neurochem 1998c;70:391-6.

Lowry JP, Fillenz M. Real-time monitoring of brain energy metabolism in vivo using microelectrochemical sensors: the effects of anesthesia. Bioelectrochemistry 2001;54:39-47.

Lowry JP, O’Neill RD. Neuroanalytical chemistry in vivo using electrochemical sensors. In: Grimes CA, Dickey EC, Pishko MV, editors. Encyclopedia of sensors, X. California, USA: American Scientific Publishers; 2006. p. 1-23.

Lowry JP, Griffin K, McHugh SB, Lowe AS, Tricklebank M, Sibson NR. Real-time electrochemical monitoring of brain tissue oxygen: a surrogate for functional magnetic resonance imaging in rodents. Neuroimage 2010;52:549-55.

Marlatt MW, Lucassen PJ. Neurogenesis and Alzheimer's disease: biology and pathophysiology in mice and men. Curr Alzheimer Res 2010;7:113-25.

Martin SJ, Grimwood PD, Morris RG. Synaptic plasticity and memory: an evaluation of the hypothesis. Annu Rev Neurosci 2000;23:649-711.

McDougal Jr DB, Ferrendelli JA, Yip V, Pusateri ME, Carter JG, Chi MM, et al. Use of nonradioactive 2-deoxyglucose to study compartmentation of brain glucose metabolism and rapid regional changes in rate. Proc Natl Acad Sci USA 1990;87:1357-61.

McHugh SB, Fillenz M, Lowry JP, Rawlins JN, Bannerman DM. Brain tissue oxygen amperometry in behaving rats demonstrates functional dissociation of dorsa and ventral hippocampus during spatial processing and anxiety. Eur J Neurosci 2011;33:322-37.

McMahon CP, Rocchitta G, Serra PA, Kirwan SM, Lowry JP, O'Neill RD. Control of the oxygen dependence of an implantable polymer/enzyme composite biosensor for glutamate. Anal Chem 2006a;78:2352-9.

McMahon CP, Rocchitta G, Serra PA, Kirwan SM, Lowry JP, O'Neill RD. The efficiency of immobilised glutamate oxidase decreases with surface enzyme loading: an electrostatic effect, and reversal by a polycation significantly enhances biosensor sensitivity. Analyst 2006b;131:68-72.

McMahon CP, Rocchitta G, Kirwan SM, Killoran SJ, Serra PA, Lowry JP, et al. Oxygen tolerance of an implantable polymer/enzyme composite glutamate biosensor displaying polycation-enhanced substrate sensitivity. Biosens Bioelectron 2007;22:1466-73.

McNay EC, Gold PE. Extracellular glucose concentrations in the rat hippocampus measured by zero-net-flux: effects of microdialysis flow rate, strain, and age. J Neurochem 1999;72:785-90. 
McNay EC, Fries TM, Gold PE. Decreases in rat extracellular hippocampal glucose concentration associated with cognitive demand during a spatial task. Proc Natl Acad Sci USA 2000;97:2881-5.

McNay EC, McCarty RC, Gold PE. Fluctuations in brain glucose concentration during behavioral testing: dissociations between brain areas and between brain and blood. Neurobiol Learn Mem 2001;75:325-37.

McNay EC, Sherwin RS. From artificial cerebro-spinal fluid (aCSF) to artificial extracellular fluid (aECF): microdialysis perfusate composition effects on in vivo brain ECF glucose measurements. J Neurosci Methods 2004a;132:35-43.

McNay EC, Sherwin RS. Effect of recurrent hypoglycemia on spatial cognition and cognitive metabolism in normal and diabetic rats. Diabetes 2004b:53:418-25.

Menon RS, Ogawa S, Kim SG, Ellermann JM, Merkle H, Tank DW, et al. Functional brain mapping using magnetic resonance imaging. Signal changes accompanying visual stimulation. Invest Radiol 1992;2:S47-53.

Minichiello L. TrkB signalling pathways in LTP and learning. Nat Rev Neurosci 2009;10:850-60.

Morales-Villagrán A, Beltrán-Ramírez R, López-Pérez SJ, Palomera-Ávalos V, Medina-Ceja L. A capillary fraction collector coupled to a fluorescence reader: a novel device to continuously quantify glutamate during microdialysis. Neurochem Res 2012;37:1457-64.

Morris RG, Garrud P, Rawlins JN, O'Keefe J. Place navigation impaired in rats with hippocampal lesions. Nature 1982;297:681-3.

Morris RG, Moser EI, Riedel G, Martin SJ, Sandin J, Day M, et al. Elements of a neurobiological theory of the hippocampus: the role of activity-dependent synaptic plasticity in memory. Philos Trans R Soc Lond B Biol Sci 2003;358:773-86.

Nair PK, Buerk DG, Halsey Jr JH. Comparisons of oxygen metabolism and tissue $\mathrm{PO}_{2}$ in cortex and hippocampus of gerbil brain. Stroke 1987;18:616-22.

Nasrallah FA, Garner B, Ball GE, Rae C. Modulation of brain metabolism by very low concentrations of the commonly used drug delivery vehicle dimethyl sulfoxide (DMSO). J Neurosci Res 2008;86:208-14.

Netchiporouk L, Shram N, Salvert D, Cespuglio R. Brain extracellular glucose assessed by voltammetry throughout the rat sleep-wake cycle. Eur J Neurosci 2001;13:1429-34

Ogawa S, Lee TM, Kay AR, Tank DW. Brain magnetic resonance imaging with contrast dependent on blood oxygenation. Proc Natl Acad Sci USA 1990;87:9868-72.

O'Keefe J, Nadel L. The hippocampus as a cognitive map. UK: Oxford University Press; 1978 .
O'Neill RD, Grünewald RA, Fillenz M, Albery WJ. Linear sweep voltammetry with carbon paste electrodes in the rat striatum. Neuroscience 1982;7: 1945-54.

Qin S, van der Zeyden M, Oldenziel WH, Cremers TIFH, Westerink BHC. Microsensors for in vivo measurement of glutamate in brain tissue. Sensors 2008;8:6860-84.

Rex A, Bert B, Fink H, Voigt JP. Stimulus-dependent changes of extracellular glucose in the rat hippocampus determined by in vivo microdialysis. Physiol Behav 2009;98:467-73.

Russell DM, Garry EM, Taberner AJ, Barrett CJ, Paton JF, Budgett DM, et al. A fully implantable telemetry system for the chronic monitoring of brain tissue oxygen in freely moving rats. J Neurosci Methods 2012;204:242-8.

Sandberg M, Butcher SP, Hagberg H. Extracellular overflow of neuroactive amino acids during severe insulin-induced hypoglycemia: in vivo dialysis of the rat hippocampus. J Neurochem 1986;47:178-84.

Scoville WB, Milner B. Loss of recent memory after bilateral hippocampal lesions. J Neurol Neurosurg Psychiatry 1957;20:11-21.

Serres S, Bezancon E, Franconi JM, Merle M. Ex vivo analysis of lactate and glucose metabolism in the rat brain under different states of depressed activity. J Bio Chem 2004;279:47881-9.

Serres S, Bezancon E, Franconi JM, Merle M. Ex vivo NMR study of lactate metabolism in rat brain under various depressed states. J Neurosci Res 2005;79: $19-25$.

Shram NF, Netchiporouk LI, Martelet C, Jaffrezic-Renault N, Cespuglio R. Brain glucose: voltammetric determination in normal and hyperglycaemic rats using a glucose microsensor. Neuroreport 1997;8:1109-12.

Tian F, Gourine AV, Huckstepp RT, Dale N. A microelectrode biosensor for real time monitoring of L-glutamate release. Anal Chim Acta 2009;645:86-91.

Uematsu M, Takasawa M, Hosoi R, Inoue O. Uncoupling of flow and metabolism by chloral hydrate: a rat in-vivo autoradiographic study. Neuroreport 2009;20:219-22.

Yamada A, Yamamoto K, Imamoto N, Momosaki S, Hosoi R, Yamaguchi M, et al. Lactate is an alternative energy fuel to glucose in neurons under anesthesia. Neuroreport 2009;20:1538-42.

Yang H, Peters JL, Michael AC. Coupled effects of mass transfer and uptake kinetics on in vivo microdialysis of dopamine. J Neurochem 1998;71:684-92.

Zimmerman JB, Wightman RM. Simultaneous electrochemical measurements of oxygen and dopamine in vivo. Anal Chem 1991;63:24-8. 